\title{
JPMB: qualificação da performance no contexto da educação musical comunitária em cidades interioranas de Alagoas
}

JPMB: qualification of performance in the context of community music education in inner cities of Alagoas

Marcos dos Santos Moreira ${ }^{1}$ Universidade Federal de Alagoas moreiraufal@gmail.com 


\section{Resumo}

Este artigo relata o movimento de educação comunitária gratuita promovido pela Universidade Federal de Alagoas no projeto denominado JPMB (Jornada Pedagógica para Músicos de Banda), através do Grupo de Pesquisa Cemupe (Centro de Musicologia de Penedo), no estado de Alagoas. Esta ação de extensão, além de percorrer alguns municípios interioranos, carateriza-se hoje como um processo de aprendizado coletivo e social por meio do ensino musical. Faz uma abordagem de como a academia pode se mobilizar para debater sobre música e políticas públicas sobre a educação musical no interior de Alagoas, no Nordeste, e as parcerias com governos municipais, estaduais e federal juntamente com a iniciativa privada e instituições de ensino de outros países.

Palavras-chave: Educação musical comunitária; musicologia social; políticas públicas.

\section{Abstract}

This article reports the free community education movement promoted by the Federal University of Alagoas in the project called JPMB - Pedagogical conferences for fanfare musicians, through the Research Group CEMUPE - Penedo Musicology Center in the State of Alagoas. This extension program also covers some municipalities in the interior of the state, and it characterizes itself today as a process of collective and social learning through musical teaching. It approaches how the academy can mobilize to debate music and public policies on music education in the interior of Alagoas, in the northeast and partnerships with municipal, state and federal governments together with the private sector and educational institutions with others countries.

Keywords: Community music education; social musicology; public policies. 


\section{INTRODUÇÃO}

Desde 2008, inserido nas ações de extensão do curso de Música na Universidade Federal de Alagoas, com a criação do Grupo de Pesquisa Metodologia e Concepção Social do Ensino Coletivo Instrumental, iniciou-se um levantamento pedagógico e musicológico das bandas filarmônicas de Alagoas. Em 2018 sua nomenclatura foi alterada para Cemupe (Centro de Musicologia de Penedo), mantendo a mesma característica de suas linhas de pesquisa de 2009. Instituem-se vários eventos decorrentes, que se seguem:

- Colóquio de Música Popular, evento que discutia a atuação dos músicos na cidade de Maceió e debates sobre a profissionalização desse cotidiano;

- Revista eletrônica Musifal, aberta não só aos professores, mas aos alunos de Graduação em Música do país;

- Continuidade dos Seminários de Pesquisa, a princípio criados pela professora Regina Cajazeira, como efetiva da Ufal;

- MAPT (Musicalização Através do Piano e do Teclado). Inicialmente, uma compilação autorizada do projeto implementado na UFBA na década de 1990, no qual fiz toda a minha formação acadêmica, denominado Oficinas de Piano em Grupo, do qual fui monitor durante seis anos na minha Graduação em Música. ${ }^{2}$

Em 2009 outro movimento denominado JPMB (Jornada Pedagógica para Músicos de Banda) fora criado, cuja ideia inicialmente era implantar uma relação entre a academia, os alunos de bandas de música ou não e os egressos e ingressantes no curso de Licenciatura em Música da Ufal, bem como o público externo em geral.

Houve a busca sobre a reflexão da então recém-promulgada Lei $\mathrm{n}$ 일.769, a ponte entre o ensino universitário - com suas grades pedagógicas, muitas vezes engessadas sob o ponto de vista do que se aplicava na prática instrumental, fora das esferas da graduação - e a comunidade musical. Desde o ano de 2009, foi verificado que o curso de Graduação em Música da Ufal, pelo diminuto quadro docente e estrutura física, no limite do seu funcionamento, talvez necessitasse de projetos que pudessem mostrar ao meio acadêmico e à sociedade alagoana sua função relevante, educacional e artística, além do fomento cognitivo ao desenvolvimento profissional no ato da docência escolar.

Entre 2010 e 2013, durante a realização do doutorado pelo então coordenador do projeto entre Brasil e Portugal, obteve-se a oportunidade de desenvolver parceria institucional entre a Ufal e o Instituto Piaget, na cidade de Viseu. Assim, com a instauração do grupo de pesquisa da Ufal, por questões estratégicas, a JPMB alterou a nomenclatura para Cemupe (Centro de Musicologia de Penedo), ${ }^{3}$ registrada na base de dados do Diretório de Grupos de Pesquisa do CNPq, tendo quatro linhas bem-definidas:

Tal modelo de projeto de extensão, denominado na época de Imit e Oficinas de Piano em Grupo, foi criado na década de 1990 por Alda Oliveira, baseado nos estudos de Maria de Lourdes Junqueira Gonçalves, da Unirio, em 1980. Este projeto foi coordenado na UFBA pela Prof. ${ }^{\text {D }}$ Dra. Diana Santiago.

3 Com o deslocamento do projeto para a cidade de Penedo, o Grupo metodologia e Concepção Social passa a se denominar Cemupe, com o apoio e parcerias com as instituições públicas deste município. 
1- a preservação das instituições filarmônicas e seus contextos sociais e pedagógicos;

2- a inserção científica da Ufal nestes grupos, no sentido de apoio, registro e publicações;

3- ratificações das temáticas propostas do grupo de pesquisa, como a relação cultural das bandas com as nossas etnias e cultura, bem como a influência portuguesa;

4- a afirmação de gênero em grupos tradicionais e o contexto feminino nas bandas de música.

Desde então, a internacionalização deste projeto, com vários desdobramentos de intercâmbios luso-brasileiros e a ampliação da JPMB, deslocando-se do câmpus Maceió para as cidades interioranas de Alagoas, era um dos pilares para se criar um festival de porte internacional, com os mesmos moldes de outros festivais similares do país, a exemplo do Civebra, no Distrito Federal; Campos do Jordão, em São Paulo; Eleazar de Carvalho, em Fortaleza, entre outros. Entretanto, nossa proposta era oferecer à comunidade um evento totalmente gratuito, sem taxas ou pré-avaliações.

A interiorização era um caminho sem retorno no sentido da propagação do que o grupo de pesquisa estava realizando dentro dos programas de pesquisa e extensão da Ufal, e isto só foi possível de fato a partir de $2014,{ }^{4}$ quando os setores logísticos da reitoria compartilharam a ideia. No caso da JPMB, o movimento no referido ano teve a oportunidade de expandir-se para os polos da Ufal, ${ }^{5}$ por serem próximos de dezenas de cidades de Alagoas com diversificados grupos musicais e principalmente bandas de música que no Nordeste também são denominadas filarmônicas. Muitos desses integrantes de bandas faziam anualmente os testes de aptidão para o curso de Licenciatura em Música da Ufal - dezenas eram aprovados. Era necessário, portanto, levar a música e seu idioma acadêmico, não como imposição, evidentemente, mas como algo que somasse e despertasse o interesse deste público fora do eixo capital-região metropolitana maceioense sobre o nível superior e a profissionalização. Tendo isso em vista, realizamos oficinas instrumentais que alcançassem um número maior de participantes, já que o perfil da JPMB se baseava na democratização do ensino gratuito na perspectiva de educação de extensão majoritariamente comunitária.

A responsabilidade que nos convocou para um projeto ou programa, dentro dessas diretrizes das linhas do grupo, nos fez acreditar numa musicologia social, engajada nos princípios de uma educação libertária "freireana", que não estivesse apenas vinculada à música em seu papel específico e acadêmico, mas dialogando com seus pares, nas áreas das humanidades. Locke (2015), no texto "Musicology and/as social concern: imagining the relevant musicologist", já abordava tal diálogo com outras áreas, considerando o papel do pesquisador em música e sua prática social.

Eu diria: sim. Músicos (incluindo pesquisadores musicais), como quaisquer outros indivíduos, precisam aprender a assumir um papel ativo no desenvolvimento de uma sociedade mais justa, ao invés de cuidar, sempre silenciosamente, do seu ou do nosso jardim. Pode ser encorajador, ao considerarmos este problema de enveredar para além da música, com a finalidade de efetuar mudanças no

\footnotetext{
$4 \quad$ Nos anos de 2012 e 2013, a JPMB não foi realizada integralmente.

5 Além do câmpus principal, A. C. Simões, em Maceió, a Ufal tem os câmpus Arapiraca e Santana do Ipanema.
} 
mundo como um todo, lembrar que não somos os primeiros da área de música a fazer isto. (LOCKE, 2015, p.44).

Autores como Kerman (1985), Kramer (1992) e Rosand (1995) defendem a linha humanística e plural na direção da musicologia social. Tal pensamento fez com que nos aproximássemos de alguns conceitos referentes à New Musicology no contexto das análises concomitantes aos pares nas ciências humanas deste enfoque comunitário e corroborando no estudo musicológico possível, inserido no diálogo da educação, história e sociologia, por exemplo. Dessa forma, possibilitou a afirmação no contexto comunidade e música nos dados realizados pelo Cemupe em alusão à JPMB. No Brasil, autores como Neto e Tramontina (2001, p.7) esclarecem:

\begin{abstract}
A partir, sobretudo, da década de 1980, alguns musicólogos ingleses e norteamericanos, propondo um entendimento hermenêutico da música e da própria disciplina, começaram a atentar para as falácias e restrições decorrentes das premissas historiográficas e de seu papel canonizador, bem como do afunilamento do termo musicologia. A esta tendência crítica, deu-se o nome de New Musicology. Buscando um conceito multidisciplinar que considerasse a música como, primeiramente, agente de representação cultural capaz de tornar manifesto os mecanismos de crise e de mudança nos sistema culturais e ideológicos e, também, como produtora de significados que vão além do puramente musical, a New Musicology questionou a prática tradicional da disciplina e sua herança epistemológica iluminista e positivista.
\end{abstract}

Ratificando a recorrência para as áreas afins, como apoio referencial teórico nos textos produzidos e apresentados nos congressos e ações da JPMB, esta musicologia social se une à educação musical, por entender nestas ações a crescente participação de núcleos sociomusicais que já praticam um sistema educacional musical.

Em relação às bandas, a JPMB, ainda que encontrasse resistência no diálogo das metodologias propostas e oferecidas devido ao rígido e incrédulo pensamento de muitas direções administrativas e pedagógicas destes grupos, em termos quantitativos atingia praticamente boa parte desta busca pelos participantes do intercâmbio cognitivo musical e os debates da pesquisa propostos pela JPMB.

A estrutura filosófica das ações na JPMB, em relação à oportunização coletiva e citando Gadotti (2012) sobre a educação comunitária, nos alerta sobre o viés da educação popular, que tem por filosofia não esconder a relação política em seu caráter social.

É o que acontece com a educação popular, a educação social e a educação comunitária. Elas se situam no mesmo campo de significação pedagógica, o campo democrático e popular. Contudo, apesar desta afinidade ideológica, como são educações históricas, elas também podem ter conotações diferentes. $E$ isso não se constituiu em deficiência, mas em riqueza. Um mosaico de experiências, teorias e práticas compõem esse campo. (GADOTTI, 2012, p.5).

Assim, a universidade pública e a parceria dos agentes, com apoio também da iniciativa privada (com os representantes do mercado da música do setor industrial de instrumentos musicais), foram as metas da articulação da JPMB em sua partícula do 
ideal de uma educação musical ampla deste conceito, cumprindo seu papel socioeducacional e o exercício da cidadania na prática.

Pensamos, assim, tratar o movimento na relação da realidade interiorana, muitas vezes, no caso das filarmônicas e partícipes de movimentos musicais diversos nestes municípios, sem o acesso à ampliação pedagógica e formação profissional in loco, oportunizando, sem descartar toda a experiência dos mestres locais, a possibilidade do diálogo. Não queremos afirmar, portanto, que se tratava de uma invasão ao meio estabelecido nestas sociedades musicais, mas do acréscimo de um universo real profissional que estes alunos músicos pudessem alcançar: o respeito à tradição e, principalmente, à "identidade do indivíduo", como afirmava Paulo Freire sobre a questão da liberdade como agente da educação.

[...] as sociedades a que se nega o diálogo-comunicação e, em seu lugar, se thes oferecem "comunicados", resultantes de compulsão ou "doação", se fazem preponderante "mudas". O mutismo não é propriamente inexistência de resposta. É resposta a que falta teor marcadamente crítico. Não há realmente, como se possa pensar em dialogação com a estrutura do grande domínio, com o tipo de economia que o caracterizava, marcadamente autárquico. A dialogação implica uma mentalidade que não floresce em áreas fechadas, autarquizadas. Estas, pelo contrário, constituem-se num clima ideal para o antidiálogo. Para a verticalização das imposições. (FREIRE, 1980, p.69).

A universidade no Brasil, provedora da educação pública, sendo a extensão e importante esfera da formação das pessoas, nos contextos constitucionais das políticas públicas para educação, se atrela na sua extensão ao acesso a camadas ainda não concludentes dos níveis de ensino anterior (educação básica fundamental e ensino médio). Vimos este projeto como uma abertura ou "cartão de visita" do que o ensino superior poderá contribuir na especificidade da área nos tempos posteriores destes agentes. Assim como o público da comunidade, pensamos que:

As classes populares reivindicam escola pública, mas não querem apenas a extensão da escola burocrática e elitista do Estado. Querem que essa escola acolha também os seus saberes e sonhos e seja radicalmente democrática. Querem discutir a função social dessa escola, colocando em questão os seus conteúdos e sua gestão. Esse novo movimento não nega o papel do Estado como o principal articulador das políticas sociais. (GADOTTI, 2012, p.5).

Portanto um dos fatores desta interiorização se baseou no diagnóstico e no perfil do público-alvo, além de questões didáticas da inclusão da extensão nos municípios, debatidas nos foruns anteriores e o diálogo entre os grupos filarmônicos; se a distância física das mesmas comprometia o acesso ao ensino qualificado; como este diálogo ocorria; o acesso a aulas e palestras por docentes de renome nacional e internacional dialogando de fato com a academia, e se tais motivos citados era possível tal ação. 


\section{O MODELO, A METODOLOGIA E OS RESULTADOS}

Para uma melhor compreensão do público-alvo, o então grupo de pesquisa Metodologia e Concepção Social do Ensino Coletivo Instrumental se baseou em questões do movimento do ensino musical nas cidades interioranas; no acesso dos alunos de música às plataformas digitais, ainda sobre performance instrumental; no contato dos mesmos com oficinas instrumentais didáticas ou com docentes da área de performance em encontros e congressos oferecidos pela Ufal ou outras instituições; na análise estrutural das sedes das sociedades musicais e o acesso gratuito com ajuda estatal ou com parceria público-privado.

Tais questões foram baseadas no modelo de análise acima de Moscarola (1990, p.105), abordadas na minha tese de 2013 sobre a formulação de questionários e entrevistas para esta formulação de perguntas, de hipóteses em grupos, que estão atreladas a outras questões externas do ambiente. Ou seja, realizamos um diagnóstico para obter justificativas mais exatas da implantação desta extensão no interior de Alagoas.

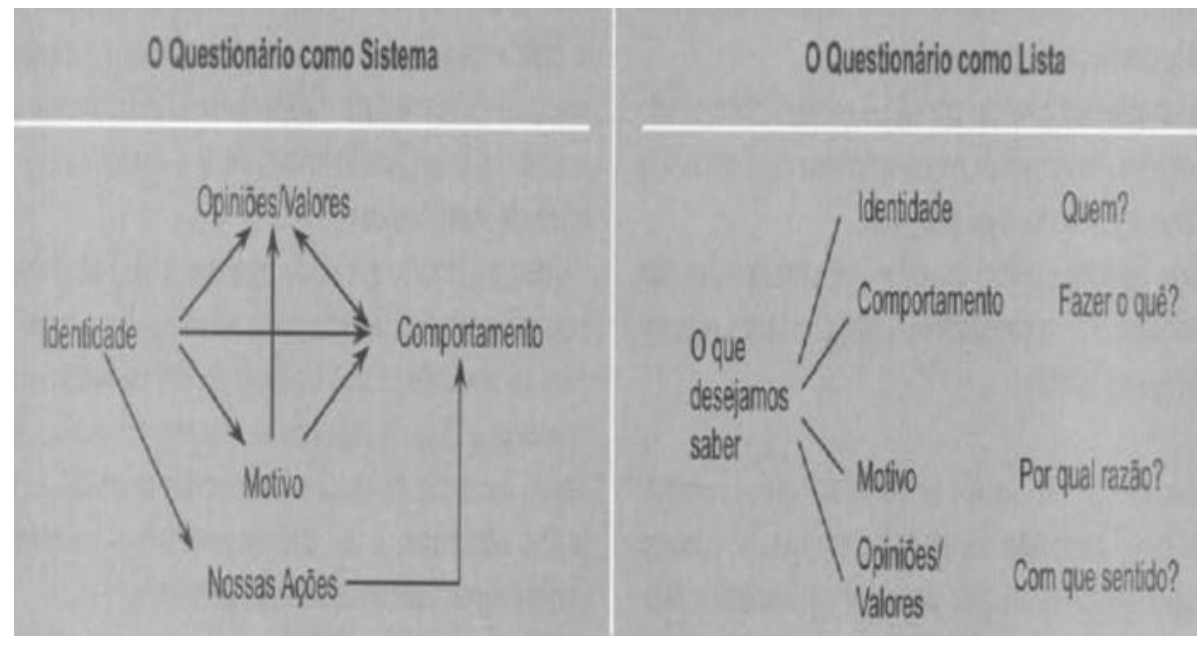

Fig 1: Modelo de Moscarola (1990)

Assim, o grupo de pesquisa poderia, de alguma forma, criar as hipóteses já relatadas anteriormente para que a ação comunitária obtivesse um diagnóstico de referência, para depois montar a logística da ação do projeto e estabelecer o número crescente destes alunos fora do ambiente - filarmônico ou não -, preservando sempre a "identidade do indivíduo", como cita Paulo Freire, e a identidade cultural local nas oficinas propostas pelos nossos professores convidados. Freitas destaca estas ações:

Moscarola desenvolve interessante abordagem a respeito do questionário e de sua elaboração, definindo primeiro como todo o grande macroambiente que cerca e define o contexto: cultura e modo de vida, economia, técnicas, sociedade, organizações, locais, geografia; depois se aproxima mais com aspectos de marketing, como comunicação e publicidade... Faz uma triangulação dos métodos de observação ao conteúdo, associando o tema ao significado de observação (identidade, comportamentos e valores), à natureza do objeto (fatos, 
comportamentos, opiniões) e aos meios (ou métodos de observação, ou seja, observação direta, entrevista fechada, entrevista semiaberta ou entrevista aberta). Sua ênfase é, ainda, a de que há diversas maneiras de abordar o tema. (FREITAS, 2000, p.4).

Toda ação comunitária também provém das parcerias entre essas políticas públicas que promovem estas possibilidades através de ONGs ou outros formatos gerados pelas próprias sociedades musicais e que assim podem gerir as metas da JPMB neste contexto. ${ }^{6}$

\section{O perfil dos atendidos}

Foram detectados basicamente quatro perfis de estudantes de música nas enquetes resultantes das edições do projeto JPMB, incluindo as edições interioranas:

1- estudantes de graduação ou de cursos técnicos vizinhos a Alagoas, sendo as universidades federais e os institutos federais, em sua maioria;

2- estudantes de outras áreas, mas que têm na música um segundo objeto de estudo em seus contextos cotidianos;

3- alunos de escolas públicas de diversos estados que participam de projetos de música ou que são de grupos musicais compostos nestas unidades de ensino, geralmente atrelados às atividades de disciplinas artísticas nas esferas municipais e estaduais;

4- grupo com perfil mais próximo da identidade do projeto, que é o contexto filarmônico.

Geralmente os inscritos são alunos que percorrem as aulas no formato da tradição bandística. O período de formação dos integrantes de sociedades musicais nestas bandas de música dura em média um ano, abordando primeiramente teoria musical e, logo após, o aprendizado instrumental. Ou seja, temos um público com níveis diferentes, sendo necessário equilibrar o nível das turmas instrumentais oferecidas. Como exemplo, destacamos o processo de registro coordenado e realizado em parceria com a JPMB, pelo professor José Luann Veiga em sua plataforma Ecim (Espaço de Compreensão e Invenção Musical), 7 desde a edição de 2015, que é sempre atualizado a cada evento. $O$ gráfico a seguir, baseado na enquete on-line disponível na página de inscrição, ${ }^{8}$ demonstra os dados anuais dos perfis dos inscritos e sua relação com o conhecimento musical.

\footnotetext{
$6 \quad$ Nestes anos de pesquisa, destacamos ações em sociedades musicais que transformaram suas sedes em escolas com cronogramas e avaliações próprias de ensino, oferecendo gratuitamente cursos e promovendo encontros em suas sedes. São exemplos a Sociedade Musical Curica (Pernambuco), a Sociedade Musical Cruzeta (Rio Grande do Norte), a Fundação Música e Vida de São Caetano (Pernambuco), entre outras em Alagoas e outros municípios nordestinos.

7 Plataforma gerida nas ações do Cemupe, responsável pela salvaguarda dos dados do projeto e parceiro da JPMB.

8 Disponível em: www.ecimusical.com/jpmb.
} 


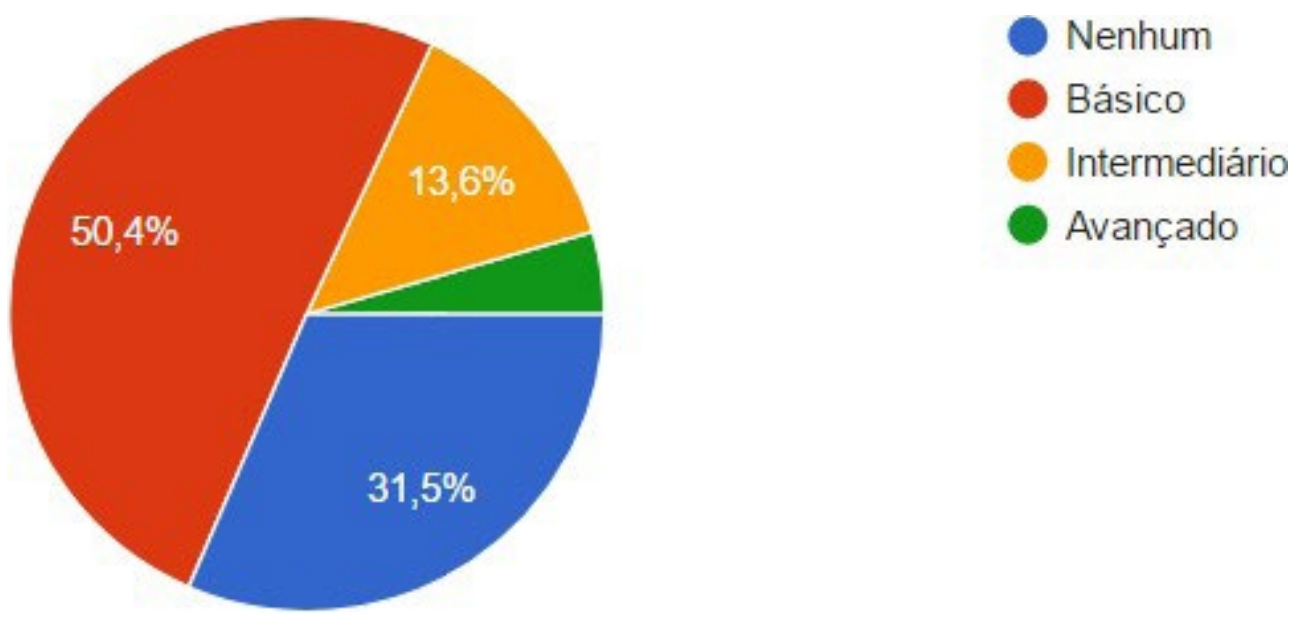

Gráfico 1: Dados da plataforma ECIM.2015

Para estes alunos interessados, a JPMB é a oportunidade de obter caminhos pedagógicos para outras metodologias de celeridade na habilidade performática, já que o corpo docente deste também é oriundo de filarmônicas e projetos sociomusicais, em sua grande maioria.

É bastante salutar que as oficinas oferecidas pelos docentes convidados tenham caráter pedagógico livre em sua estrutura individual em cada atividade; apenas sugerimos que estivesse de acordo com o perfil do alunado participante. A alternância de docentes também oferece uma gama de possibilidades dos caminhos da prática. Nestes anos, foram oferecidas as seguintes atividades:

- Oficinas de instrumentos: clarinete, saxofone, trompete, tuba, bombardino, trompa, fagote, oboé, trombone, violão, violino, cravo, piano;

- Oficinas especiais: Prática de Regência Banda, Práticas de Grupo de Câmara, Oficinas de Arranjo e Orquestração, Vivências de Educação Musical, Introdução à Musicologia;

- Fóruns de musicologia, Fóruns de Maestro de Bandas, Fóruns de Educação e Música, Fóruns de Cultura e o subprojeto JPMB nas Escolas. ${ }^{9}$

- Concertos nos espaços públicos, prédios coloniais e turísticos locais e praças;

- Apresentações de comunicações e artigos propostos na revista Musifal.

A JPMP conta com um corpo organizacional que envolve alunos da Graduação em Música da Ufal, voluntários e bolsistas; professores e técnicos do curso de Graduação em Música, Turismo e História; além do apoio das esferas administrativas da universidade, como a Propep (Pró-Reitoria de Pesquisa), a Proex (Pró-reitoria de Extensão Universitária), a Proinst (Pró-Reitoria Estudantil), a Ascom (Assessoria de Comunicação) e a CAC (Coordenação de Assuntos Culturais).

No quadro a seguir serão expostos os anos e as ações para o melhor entendimento do processo histórico e estrutural da JPMB entre 2009 e 2019. Em negrito o ano e as cidades do interior de Alagoas beneficiadas com o projeto. 


\begin{tabular}{|c|c|c|c|c|}
\hline Ano & Cidade (AL) & Local & Ações pedagógicas & $\begin{array}{l}\text { Número de certificados }{ }^{10} / \\
\text { Perfil }\end{array}$ \\
\hline 2009 & Maceió & $\begin{array}{l}\text { Auditório do Espaço } \\
\text { Cultural da Ufal }\end{array}$ & $\begin{array}{l}\text { Palestra sobre o méto- } \\
\text { do Da Capo }\end{array}$ & $\begin{array}{l}90 \text { certificados } \\
\text { Perfil dos participantes: } \\
\text { Graduados em Música, in- } \\
\text { tegrantes de filarmônicas, } \\
\text { professores das sociedades } \\
\text { musicais e da Ufal }\end{array}$ \\
\hline 2009 & Maceió & $\begin{array}{l}\text { Auditório do Espaço } \\
\text { Cultural da Ufal }\end{array}$ & $\begin{array}{l}\text { Palestra sobre o méto- } \\
\text { do Da Capo e oficinas } \\
\text { de trompa }\end{array}$ & $\begin{array}{l}120 \text { certificados } \\
\text { Participantes: Graduados } \\
\text { em Música, integrantes de } \\
\text { filarmônicas, professores } \\
\text { das sociedades musicais e } \\
\text { da Ufal }\end{array}$ \\
\hline 2010 & Maceió & $\begin{array}{l}\text { Auditório do Espaço } \\
\text { Cultural da Ufal }\end{array}$ & $\begin{array}{l}\text { Lançamento do DVD do } \\
\text { professor Bohumil Med }\end{array}$ & $\begin{array}{l}130 \text { certificados } \\
\text { Participantes: Graduados } \\
\text { em Música, integrantes de } \\
\text { filarmônicas, professores } \\
\text { das sociedades musicais e } \\
\text { da Ufal }\end{array}$ \\
\hline 2010 & Maceió & $\begin{array}{l}\text { Auditório do Espaço } \\
\text { Cultural da Ufal }\end{array}$ & $\begin{array}{l}\text { Modelo Festival defini- } \\
\text { tivo: Palestras, lança- } \\
\text { mento de livros, oficinas } \\
\text { instrumentais, bandas } \\
\text { de música de outros } \\
\text { estados }\end{array}$ & $\begin{array}{l}150 \text { certificados } \\
\text { Participantes: Graduados } \\
\text { em Música e integrantes de } \\
\text { filarmônicas, professores } \\
\text { das sociedades musicais e } \\
\text { da Ufal }\end{array}$ \\
\hline 2013 & Maceió & $\begin{array}{l}\text { Auditório do Espaço } \\
\text { Cultural da Ufal }\end{array}$ & $\begin{array}{l}\text { Modelo Festival defini- } \\
\text { tivo: Palestras, lança- } \\
\text { mento de livros, oficinas } \\
\text { instrumentais, bandas } \\
\text { de música de outros } \\
\text { estados }\end{array}$ & $\begin{array}{l}221 \text { certificados } \\
\text { Participantes: Graduados } \\
\text { em Música, integrantes de } \\
\text { filarmônicas, professores } \\
\text { das sociedades musicais e } \\
\text { da Ufal }\end{array}$ \\
\hline 2014 & Arapiraca & Escola de Artes & $\begin{array}{l}\text { Modelo Festival definiti- } \\
\text { vo na cidade do inte- } \\
\text { rior. Palestras, lança- } \\
\text { mento de livros, oficinas } \\
\text { instrumentais, bandas } \\
\text { de música de outros } \\
\text { estados }\end{array}$ & $\begin{array}{l}230 \text { certificados } \\
\text { Participantes: }:^{11} \text { Integrantes } \\
\text { de filarmônicas, professo- } \\
\text { res das sociedades musi- } \\
\text { cais e da Ufal, pesquisa- } \\
\text { dores de outros estados e } \\
\text { países }\end{array}$ \\
\hline
\end{tabular}




\begin{tabular}{|c|c|c|c|c|}
\hline 2015 & Arapiraca & Escola de Artes & $\begin{array}{l}\text { Modelo Festival } \\
\text { definitivo na cidade } \\
\text { do interior. Palestras, } \\
\text { lançamento de livros, } \\
\text { oficinas instrumentais, } \\
\text { bandas de música de } \\
\text { outros estados }\end{array}$ & $\begin{array}{l}253 \text { certificados } \\
\text { Participantes Integrantes } \\
\text { de filarmônicas, Professo- } \\
\text { res das sociedades musi- } \\
\text { cais e da Ufal, pesquisa- } \\
\text { dores de outros estados e } \\
\text { países }\end{array}$ \\
\hline 2016 & $\begin{array}{l}\text { Marechal } \\
\text { Deodoro }\end{array}$ & $\begin{array}{l}\text { Vários prédios } \\
\text { coloniais }\end{array}$ & $\begin{array}{l}\text { Parceria com o } \\
\text { Sesc e a junção } \\
\text { com a plataforma } \\
\text { Ecim (Espaço de } \\
\text { Compreeensão e } \\
\text { Invenção Musical), }{ }^{12} \\
\text { patrocínio por edital da } \\
\text { Fundação de Amparo } \\
\text { a Pesquisa de Alagoas } \\
\text { (Fapeal), apoio do Edital } \\
\text { Paep-Capes nesta } \\
\text { edição }\end{array}$ & $\begin{array}{l}355 \text { certificados } \\
\text { Participantes: Integrantes } \\
\text { de filarmônicas, professo- } \\
\text { res das sociedades musi- } \\
\text { cais e da Ufal, pesquisa- } \\
\text { dores de outros estados e } \\
\text { países. } \\
\text { Inscrições on-line, pos- } \\
\text { sibilitando um aumento } \\
\text { considerável de participan- } \\
\text { tes. Inserção dos fóruns de } \\
\text { cultura e de maestros }\end{array}$ \\
\hline 2017 & $\begin{array}{l}\text { Marechal } \\
\text { Deodoro }\end{array}$ & $\begin{array}{l}\text { Vários prédios } \\
\text { coloniais }^{13}\end{array}$ & $\begin{array}{l}\text { ECIM (Espaço de Com- } \\
\text { preeensão e Invenção } \\
\text { Musical/CNPq), pa- } \\
\text { trocínio por edital da } \\
\text { Fundação de Amparo } \\
\text { a Pesquisa de Alagoas } \\
\text { (Fapeal) }\end{array}$ & $\begin{array}{l}450 \text { certificados } \\
\text { Participantes: Integrantes } \\
\text { de filarmônicas, professo- } \\
\text { res das sociedades musi- } \\
\text { cais e da Ufal, pesquisado- } \\
\text { res de outros } \\
\text { estados e países. } \\
\text { Consolidação dos fóruns } \\
\text { propostos. }\end{array}$ \\
\hline
\end{tabular}

12 A certificação on-line passa a ser registrada nos dados do Ecim em parceria com o Grupo de Pesquisa. A certificação chancelada pelo CNPq nos permitiu oficializar os dados nos registros Procep e Proex da Universidade Federal de Alagoas.

13 Marechal Deodoro e Penedo são cidades tombadas pelo Patrimônio Histórico Nacional, e o Iphan permite, com as respectivas autorizações, que os prédios restaurados sejam utilizados para ações culturais e pedagógicas. 


\begin{tabular}{|c|c|c|c|c|}
\hline 2018 & Penedo & $\begin{array}{l}\text { Vários prédios } \\
\text { coloniais }\end{array}$ & $\begin{array}{l}\text { Chancela da Secretaria } \\
\text { de Cultura e da Secre- } \\
\text { taria de Educação de } \\
\text { Penedo, patrocínio por } \\
\text { edital da Fundação de } \\
\text { Amparo a Pesquisa de } \\
\text { Alagoas (Fapeal) }\end{array}$ & $\begin{array}{l}750 \text { certificados } \\
\text { Mudança de nomencla- } \\
\text { tura para JPMB-Festival } \\
\text { Internacional de Música de } \\
\text { Penedo. } \\
\text { Inserção de fóruns de } \\
\text { educação e a JPMB nas } \\
\text { escolas em parceria com a } \\
\text { Semed local. } \\
\text { Participantes: Integrantes } \\
\text { de filarmônicas, professo- } \\
\text { res das sociedades musi- } \\
\text { cais e da Ufal, pesquisa- } \\
\text { dores de outros estados e } \\
\text { países. }\end{array}$ \\
\hline 2019 & Penedo & $\begin{array}{l}\text { Vários prédios } \\
\text { coloniais }\end{array}$ & $\begin{array}{l}\text { Patrocínio por edital da } \\
\text { Fundação de Amparo } \\
\text { a Pesquisa de Alagoas } \\
\text { (Fapeal) }\end{array}$ & $\begin{array}{l}\mathbf{8 5 0} \text { certificados } \\
\text { Participantes: Integrantes } \\
\text { de filarmônicas, professo- } \\
\text { res das sociedades musi- } \\
\text { cais e da Ufal, pesquisa- } \\
\text { dores de outros estados e } \\
\text { países. }\end{array}$ \\
\hline
\end{tabular}

Quadro 1: Edições da JPMB entre 2009 e 2019 e respectivas aç̃̃es. Fonte: Elaborado pelo autor.

\section{Descrição das edições}

A JPMB teve algumas transformações ao longo desses anos de existência. Abaixo uma sinopse dessas ações:

1a JPMB: Ainda em caráter experimental, surge em forma de palestra-curso sobre o ensino coletivo, em 2009;

2a JPMB: A jornada de 2009 lança a revista eletrônica Musifal, que propõe a divulgação de artigos científicos sobre professores e compositores alagoanos (1 1 a edição de capa: Hekel Tavares). Divulgação pelo convidado da edição e método Da Capo;

3a JPMB: Realizada em 2010, incluindo lançamento do DVD sobre teoria musical do renomado professor Bohumil Med. Institui-se o modelo festival com a possibilidade de oficinas de instrumento (naipes) e de debate da inserção de projetos nas escolas públicas. Maior participação das redes municipal e estadual de ensino. Tem como objetivo unir projetos de ensino musical luso-brasileiros, ganhando caráter internacional com a assinatura do convênio entre o Instituto Piaget (Portugal) e a Ufal. Palestras das parcerias de ensino entre os dois países; parceria para edição de livros entre a Sociedade Musical Curica de Pernambuco e o grupo de pesquisa na Ufal. Participação da Sociedade Musical Curica;

4a JPMB: Realizada em 2013, em Maceió. A junção com o II Encontro de Claronistas possibilitou a definitiva internacionalização da Jornada. Foram lançados três livros 
em parceria com a Filarmônica Curica e e houve a participação de quatro professores internacionais";

5a JPMB: Realizada em 2014, em Arapiraca. Faz uma junção com os concertos de música antiga. Correalização com o Ecim e o Sesc, além da criação do Fórum de Maestros com a Febamfal, a federação de bandas do estado.

6a JPMB: Realizada em 2015, em Arapiraca, com a presença dos renomados Siqueira Lima e Kleber Dessoles representando instituições alagoanas, além da presença de Alexandre Andrade e Gilvando Pereira.

7ํ JPMB: Realizada em 2016. Ampliação da participação portuguesa, com oficinas internacionais de flauta e regência, ministradas por Alexandre Andrade e Arnaldo Antonio Costa, respectivamente, uma palestra de Rui Paiva. Pela primeira vez, a JPMB ocupa espaços em prédios históricos restaurados pelo Iphan para suas atividades.

8a JPMB: Realizada em 2017, em Marechal Deodoro. Inclusão de ações de musicologia, atividade acadêmica nacional com o II Congresso da ABMUS (Associação Brasileira de Musicologia), com a presença de toda a diretoria. Houve Eventos paralelos, como os concertos solenes e o lançamento do terceiro volume da revista Musifal, com a publicação de artigos e atas do I Fórum de Maestros. 


\section{TRABALHOS SUBMETIDOS E SELECIONADOS}

\section{Congresso da ABMUS e VIII Jornadas Pedagógicas para Músicos de Banda}

Sessões de Comunicações (18/11/2017 - Auditório-CMMJR)

( $15 \mathrm{~min}$. para cada comunicação: $15 \mathrm{~min}$. ao final para debates, questões, etc.)

Sessão de Comunicações I - 8:30h-10h

\begin{tabular}{|l|l|l|}
\hline & Nome & \multicolumn{1}{c|}{ Trabalho } \\
\hline 1. & $\begin{array}{l}\text { Ana } \\
\text { Greyce } \\
\text { Moraes } \\
\text { Pereira }\end{array}$ & $\begin{array}{l}\text { Banda Sociedade Musical Penedense: A Música no Baixo } \\
\text { São Francisco Alagoano }\end{array}$ \\
\hline 2. & $\begin{array}{l}\text { Antônio } \\
\text { Tenório Filho }\end{array}$ & $\begin{array}{l}\text { Bandas de música e sociedades musicais no Rio Grande do } \\
\text { Norte no início do século XX }\end{array}$ \\
\hline 3. & $\begin{array}{l}\text { Dimison } \\
\text { Cesar } \\
\text { Vieira } \\
\text { Gomes }\end{array}$ & $\begin{array}{l}\text { O desaparecimento das bandas e dos desfiles cívicos no } \\
\text { Munićpio de Escada: uma análise baseada na História }\end{array}$ \\
\hline 4. & $\begin{array}{l}\text { Felipe Gomes } \\
\text { de Freitas }\end{array}$ & $\begin{array}{l}\text { A Prática Musical em Bandas: um estudo etnográfico sobre } \\
\text { as vivencias de um músico }\end{array}$ \\
\hline 5. $\begin{array}{l}\text { João Paulo } \\
\text { Lima }\end{array}$ & \begin{tabular}{l} 
Arquivo Musical da Lira Carlos Gomes Estância-SE \\
\hline
\end{tabular} \\
\hline
\end{tabular}

Sessão de Comunicaçōes II - 10:30h-12h

\begin{tabular}{|l|l|l|}
\hline \multicolumn{1}{|c|}{ Nome } & \multicolumn{1}{c|}{ Trabalho } \\
\hline 6. & $\begin{array}{l}\text { Aluísio Laurindo } \\
\text { Júnior }\end{array}$ & $\begin{array}{l}\text { Luthier Raul Lage: das fábricas e escolas cubanas para o } \\
\text { ensino e produção de instrumentos musicais de corda } \\
\text { dedilhada no Brasil }\end{array}$ \\
\hline 7. & $\begin{array}{l}\text { Antônio Eduardo } \\
\text { Santos }\end{array}$ & $\begin{array}{l}\text { Criação e Recriação: PIBID e um sentido de Política Pública } \\
\text { para a } \\
\text { Educação Musical }\end{array}$ \\
\hline 8. & $\begin{array}{l}\text { Rivaldo José de } \\
\text { Souza Silva }\end{array}$ & $\begin{array}{l}\text { A música do Guerreiro de Alagoas como uma proposta } \\
\text { pedagógica para banda de música }\end{array}$ \\
\hline 9. & $\begin{array}{l}\text { Wagner Santos da } \\
\text { Silva }\end{array}$ & $\begin{array}{l}\text { A importância das atividades de extensão na formação } \\
\text { acadêmica } \\
\text { do estudante de licenciatura em música }\end{array}$ \\
\hline 10. & $\begin{array}{l}\text { Aluísio Laurindo } \\
\text { Júnior }\end{array}$ & $\begin{array}{l}\text { Hugo Martínez e a presença dos ideais socialistas nas suas } \\
\text { açôes de prática, ensino e pesquisa em lutheria }\end{array}$ \\
\hline
\end{tabular}

Sessão de Comunicações III - 14h-16h

\begin{tabular}{|l|l|l|}
\hline 11. & \multicolumn{1}{|c|}{ Nome } & \multicolumn{1}{c|}{ Trabalho } \\
\hline $\begin{array}{l}\text { Alexandre Dias da } \\
\text { Nascimento Diogo B. do } \\
\text { Rodrigo C. de } \\
\text { Cerqueira }\end{array}$ & Música, Sociabilidade e Coexistência na Maré \\
\hline
\end{tabular}

Fig. 2: Lista dos artigos publicados na VII JPMB edição III da Musifal. ${ }^{14}$

\section{A 9̣ e a 10ª edições em Penedo e a educação comunitária efetivada}

Em 2018, a convite da Secretaria de Cultura de Penedo e do comércio local em reuniões com a Secretaria de Turismo e Desenvolvimento, mudamos o projeto para a cidade. A parceria do estado (município e governo do estado) e o apoio financeiro possibilitaram um maior número de oficinas e melhor logística dos grupos filarmônicos de outros municípios.

\footnotetext{
14 Artigos previamente selecionados da Musifal, a revista eletrônica do curso de Música, fundada dentro do grupos de pesquisa. Nesta
} edição também foi sede do II Congresso da ABMUS (Associação Brasileira de Musicologia). 
Naquele momento, o estado estava representado pela Universidade, pelas secretarias de Cultura do estado e do município, pela Secretaria Municipal de Educação e pela Prefeitura Municipal de Penedo.

O orçamento do Projeto JPMB foi dobrado e a sua nomenclatura foi alterada para JPMB: Festival Internacional de Música de Penedo. Definitivamente, o corpo docente e as oficinas foram ampliadas.

Nos dois anos de ações na cidade ribeirinha do São Francisco, entre 2018 e 2019, quase dois mil participantes se cadastraram na plataforma. Todo o processo do Ecim foi on-line, e o certificado foi emitido imediatamente após a atividade. Nenhuma certificação foi impressa, contribuindo também com a preservação ambiental.

Mais de 1.500 pessoas assistiram aos concertos e às apresentações na praça, e o número de artistas e filarmônicas teve crescimento constante. Como nas outras edições, nesses anos também contamos com artistas de renome internacional, inclusive em maior número. Foram 50 convidados, 10 filarmônicas, 15 grupos de câmara e solistas, 26 oficinas ofertadas e 300 alunos das redes municipal e estadual de ensino atendidos com aulas de formação de plateia no JPMB nas escolas (tema de outros textos por vir) e representantes dos municípios e estados brasileiros registrados nas certificações, ${ }^{15}$ a exemplo de São Paulo, Rio Grande do Sul, Minas Gerais, Rio de Janeiro, Bahia, Pernambuco, Goiás, Rio Grande do Norte, Sergipe, Alagoas e Ceará.

\begin{tabular}{lll}
\hline Professor convidado & Origem & Ano de atuação no projeto \\
\hline José Alípio Martins & Universidade Federal do Recôncavo da Bahia & $2009,2013,2016$ e 2018 \\
\hline Joel da Silva Barbosa & Universidade Federal da Bahia & 2009 a 2019 \\
\hline Flávio Ferreira da Silva & Universidade Federal de Alagoas & 2013 a 2019 \\
\hline Celso Benedito & Universidade Federal da Bahia & 2013,2018 e 2019 \\
\hline Bohumil Med & Universidade de Brasilia & 2010 \\
\hline Alexandre Alberto Andrade & Instituto Piaget (Portugal) & 2013 a 2019 \\
\hline Gilvando Pereira & Universidade Federal do Rio Grande do Norte & 2013,2017 e 2018 \\
\hline Henri Bok & Bufett Grupon (Holanda) & 2013 \\
\hline Paolo De Gaspari & Bufett Grupon (Itália) & 2013 \\
\hline Humberto Dantas & Sociedade Musical Cruzeta & 2015 \\
\hline Maira Kandler & Universidade Estadual de Santa Catarina & 2015 \\
\hline Kleber Dessoles Marques & Escola Técnica de Artes Alagoas & 2015 a 2019 \\
\hline Clistenes André Lisboa & Conservatório de Música & 2015 \\
\hline Humberto Dantas & Sociedade Musical Cruzeta & 2015 \\
\hline Almir Medeiros & Instituto Federal de Alagoas & 2016 \\
\hline Marco Toledo & Universidade Federal de Ceará & 2016 \\
\hline Rui Paiva Correia & Ministério da Cultura de Portugal & 2016 \\
\hline Arnaldo Antonio Costa & Conservatório do Minho (Portugal) & 2015,2016 e 2018 \\
\hline Alberto Kattar & Universidade Federal do Rio de Janeiro & 2016 \\
\hline Luciano Alves & Yamaha Instrumentos Musicais (Rio de Janeiro) & 2016 \\
\hline Frederico Meireles Dantas & Universidade Federal da Bahia & 2016 \\
\hline
\end{tabular}




\begin{tabular}{|c|c|c|}
\hline Davisson Lima & Conservatório de Música de Sergipe & 2016 \\
\hline Gilmar Tavares & Barkley Brazil (São Paulo) & 2016 a 2019 \\
\hline Elias Coutinho & Barkley Brazil (Pará) & 2016 \\
\hline Elaine Maria da Silva & Secretaria de Educação Municipal de São Paulo & 2016 a 2019 \\
\hline Maglione Santos & Escola de Música Toca do Mago (Alagoas) & 2016 \\
\hline Cibele Sabioni & Conservatório de Tatuí (São Paulo) & 2017 \\
\hline Dario Sotelo & Conservatório de Tatuí (São Paulo) & 2017 \\
\hline Iris Vieira & Universidade Federal da Paraíba & 2017 \\
\hline Mary Angela Biason & Secretaria de Cultura de Campinas (São Paulo) & 2017 a 2019 \\
\hline Manoel Vieira Junior & Universidade de Laval (Canadá) & 2017 e 2018 \\
\hline Luciana Câmara & Universidade Federal de Pernambuco & 2017 \\
\hline Jardel Souza & Conservatório Musical de Pernambuco & 2017 e 2018 \\
\hline Aurélio Souza & Secretaria Estadual de Educação de Goiás & 2017 e 2018 \\
\hline Anor Luciano Junior & Universidade Federal de Minas Gerais & 2018 \\
\hline Renato Costa Pinto & OSBA - Orquestra Sinfônica da Bahia & 2018 \\
\hline Fábio Plácido & Universidade Estadual do Amazonas & 2018 \\
\hline Flavio Ferreira da Silva & Universidade Federal de Alagoas & 2013 a 2019 \\
\hline João Paulo Oliveira & Universidade Federal do Rio Grande do Norte & 2017 \\
\hline Diósnio Machado Neto & Universidade de São Paulo & 2016 a 2019 \\
\hline David John Cranmer & Universidade Nova de Lisboa (Portugal) & 2017 e 2019 \\
\hline Débora Borges & Universidade Federal de Alagoas & 2017 \\
\hline Eduardo Lopes & Universidade de Évora (Portugal) & 2018 e 2019 \\
\hline Lilian Pereira & EscolaTécnica de Artes (Alagoas) & 2018 e 2019 \\
\hline Fernando Binder & Secretaria de Educação de São Paulo & 2018 \\
\hline Samuel Pompeo & Barkley Brazil (São Paulo) & 2018 e 2019 \\
\hline Ana Guiomar Souza & Universidade Federal de Goiás & 2019 \\
\hline Alexandre Raine & Funarte (Rio de Janeiro) & 2018 e 2019 \\
\hline Antonio Eduardo & Universidade Caólica de Santos (São Paulo) & 2018 e 2019 \\
\hline Ziliane Teixeira & Universidade Federal de Alagoas & 2018 e 2019 \\
\hline Heloisa Leone & Colégio Marista (Salvador, Bahia) & 2019 \\
\hline Wellington Mendes & Universidade Federal da Bahia & 2019 \\
\hline Cristina Tourinho & Universidade Federal da Bahia & 2019 \\
\hline Daniel Oliveira & Dadário Instrumentos (São Paulo) & 2019 \\
\hline Mozart Vieira & Fundação Musica e Vida (Pernambuco) & 2019 \\
\hline Lélio Alves & Universidade Federal da Bahia & 2019 \\
\hline Eugenio Graça & Roriz-Sescc/ Rio Grande do Nortec/ Portugal & 2019 \\
\hline José Mauricio Brandão & Universidade Federal da Bahia & 2019 \\
\hline Jairo Tadeu Brandão & Universidade Federal da Bahia & 2019 \\
\hline Fernando Lacerda & Universidade Federal do Pará & 2019 \\
\hline José Eduardo Xavier & Universidade Federal de Alagoas & 2019 \\
\hline Alfredo Moura & Universidade Federal da Bahia & 2019 \\
\hline
\end{tabular}

Quadro 2: Professores e grupos convidados em todos os anos da JPMB. ${ }^{16}$ Fonte: Elaborado pelo autor.

16 A equipe pedagógica da Ufal não consta na lista, apenas os professores das oficinas e os palestrantes. 


\section{Conclusões}

A JPMB tem sido nesses anos o maior festival de música para estudantes da área e pesquisadores afins. Transpor e transformar além dos câmpus ratifica e fortalece o posicionamento do papel da JPMB e da Universidade. A junção do poder público com a iniciativa privada e a consolidação de apoios de fomento à pesquisa mostram que nada se demonstra nos caminhos educacionais desconectados. É um sistema que deve ser aprimorado, mas que é possível. Nesses 10 anos, vimos o árduo dissabor das dificuldades burocráticas e como estes entraves muitas vezes tornam-se desmotivadores.

Em contrapartida, os resultados satisfatórios oferecidos, nesta oportunidade de extensão e pesquisa, superam todos estes obstáculos. De acordo com os próprios professores, mesmo aqueles renomados e com reconhecida experiência no meio acadêmico, a prática docente transforma suas visões de mundo. O contato com a cultura nordestina; o diálogo com alunos de diversos caminhos; a conscientização da democratização do acesso gratuito do ensino musical neste escopo e, por último, a vivência da performance por todos os envolvidos, seja na ação ou como meros espectadores, engrandecem a nossa perspectiva de continuidade da JPMB.

Neste ano de 2020, devido às medidas de isolamento social, em concordância com a Organização Mundial da Saúde no combate à Covid-19, as ações da JPMB continuam por meio dos seus canais das redes sociais sem perder a característica formativa através da programação on-line.

O festival proposto nesta extensão afirma portanto que o diálogo diacrônico e plural entre a universidade e a comunidade faz o meio acadêmico ratificar em sua conjuntura o papel educacional e a interdisciplinaridade com as áreas afins, além do campo científico musical inserido no seu contexto artístico - pedagógico. Assim, a musicologia social e a educação musical como precursora dos estudos da música neste modelo apresentado em Alagoas, em sua prática não só performática propriamente dita, mas de um movimento em prol da diversidade e da autonomia do indivíduo, cumprindo o seu papel do movimento profissional da música na sua realidade regional.

\section{Referências}

BRASIL. [Constituição (1988)]. Constituição da República Federativa do Brasil de 1988. Brasília, DF, 5 out. 1988. Disponível em: http://www.planalto.gov.br/ccivil_03/ constituicao/constituicaocompilado.htm. Acesso em: 3 out. 2020.

FREIRE, Paulo. Ação cultural para a liberdade. 2. ed. Rio de Janeiro: Paz e Terra 1977 [1975].

FREIRE, Paulo. Educação como prática da liberdade. 10. ed. Rio de Janeiro: Paz e Terra, 1980. 
FREITAS, Henrique; OLIVEIRA, Mirian et al. O método de pesquisa survey. Revista de Administração, São Paulo, 2000.

GADOTTI, Moacir. Educação Popular, educação social, educação comunitária: conceitos e práticas diversas, cimentadas por uma causa comum. In: CONGRESSO INTERNACIONAL DE PEDAGOGIA SOCIAL, 4., 2012, Campinas. Anais [...]. Campinas, 25 a 27 jun. 2012.

JPMB. Relatório de Pesquisa Extensão. Maceió: Universidade Federal de Alagoas, 2010.

JPMB. Relatório de Pesquisa Extensão. Maceió: Universidade Federal de Alagoas, 2014.

JPMB. Relatório de Pesquisa Extensão. Maceió: Universidade Federal de Alagoas, 2015.

JPMB. Relatório de Pesquisa Extensão. Maceió: Universidade Federal de Alagoas, 2019.

KERMAN, Joseph. Contemplating music: challenges to musicology. Cambridge: Harvard University Press, 1985.

KRAMER, Lawrence. The musicology of the future. Repercussions, n. 1, p. 5-18, 1992.

LOCKE, R. P. Musicologia e/como preocupação social. Per Musi, Belo Horizonte, n. 32, p. 8-52. 2015.

MACHADO NETO, Diósnio; TRAMONTINA, Leonardo. Musicologia feminista, historiografia musical e teoria compensatória: um estudo de casos. In: SIMPÓSIO INTERNACIONAL DE MUSICOLOGIA, 2., 2011, Rio de Janeiro. Anais [...]. Rio de Janeiro: UFRJ, 2011.

MOREIRA, Marcos. Mulheres nas bandas de música: uma visão do Nordeste do Brasil e do norte de Portugal. Rio de Janeiro: Publit, 2017.

MOSCAROLA, J. Enquetes et analyse de donnés. Paris: Vulbert, 1990.

ROSAND, Ellen. The musicology of the present. American Musicological Society Newsletter, v. 25, n. 1, 1995. 